\title{
Refinement of the Crystal Structure of the Aragonite Phase of $\mathrm{CaCO}_{3}$
}

\author{
B. Dickens and J. S. Bowen* \\ Institute for Materials Research \\ National Bureau of Standards \\ Washington, D.C. 20234
}

(July 31, 1970)

\begin{abstract}
Aragonite $\left(\mathrm{CaCO}_{3}\right)$ crystallizes in the unit cell $a=4.9598(5) \AA, b=7.9641(9) \AA$, and $c=5.7379(6) \AA$ at $25{ }^{\circ} \mathrm{C}$ with four formula weights in space-group Pmcn. The structure has been refined to $R_{w}=0.024$, $R=0.040$ using $765 \mathrm{x}$-ray reflections from a single crystal. The Ca ion is coordinated to nine oxygens with $\mathrm{Ca}$. . . O distances in the range 2.414(2) A to 2.653(1) $\mathrm{A}$. The two unique $\mathrm{C}-\mathrm{O}$ distances in the $\mathrm{CO}_{3}$ group are $1.288(2) \AA$ (on the mirror plane) and $1.283(1) \AA$. The two unique $\mathrm{O}-\mathrm{C}-\mathrm{O}$ angles are $119.6(2)^{\circ}$ (across the mirror plane) and $120.13(8)^{\circ}$. The distances and angles in the $\mathrm{CO}_{3}$ group are not significantly different at the 95 percent confidence level.
\end{abstract}

Key words; Calcium carbonates; carbonates; crystal structure; single crystal x-ray diffraction.

\section{Introduction}

Aragonite $\left(\mathrm{CaCO}_{3}\right)$ is found in nature as a mineral and is an important biomineral because of its presence in coral, clam shells, gallstones, and otoliths. It is isostructural with the carbonates of large divalent cations such as $\mathrm{Ba}, \mathrm{Sr}$, and $\mathrm{Pb}$.

Aragonite is less stable than the calcite phase of $\mathrm{CaCO}_{3}$ at room temperature, transforms into calcite, and is denser than calcite. Thus aragonite is a high pressure form of $\mathrm{CaCO}_{3}$. More details are available in reference [1]. ${ }^{1}$ Because of the importance of aragonite, and because of the possibility of performing calculations on the lattice energies of selected carbonates along the lines suggested by Busing [2], we have collected new x-ray data from a single crystal of aragonite and have refined the structure from the positions given in 1924 by Bragg [3].

\section{Structure Determination}

Formula (ideal): $\mathrm{CaCO}_{3}$ (aragonite phase); Unit Cell: orthorhombic with $a=4.9598(5) \AA, b=7.9641$ (9) $\AA, c=5.7379(6) \AA$ at $25{ }^{\circ} \mathrm{C}$ (calculated by least squares from $122 \theta$ values observed on a diffractometer; volume: $226.65 \AA^{3}$; radiation, $\operatorname{Mo}\left(\mathrm{K}_{\alpha 1}\right), \lambda=0.70926 \AA$; monochromator: highly oriented graphite crystal; space-group: Pmcn; contents $4\left(\mathrm{CaCO}_{3}\right)$; reciprocal lattice extinctions, $h k 0: h+k=2 n+1, h 0 l: l=2 n+1$; observed density, 2.947(2) $\mathrm{g} \cdot \mathrm{cm}^{-3}[4] ;$ calculated

*Research Associate from the American Dental Association at the National Bureau of Standards, Washington, D.C. 20234.

Figures in brackets indicate the literature references at the end of this paper. density, $2.944 \mathrm{~g} \cdot \mathrm{cm}^{-3}$; Crystal: material available was heavily twinned; a small wedge was the largest crystal fragment found which showed no evidence of twinning under optical and x-ray examination; this wedge was attached to thin borate glass fiber with clear household cement; fiber attached to insert in goniometer head with epoxy cement; origin of crystal, mineral sample \#75538 from National Museum of Natural History, Smithsonian Institute, Washington, D.C. (Supplied by J. S. White, Jr.); linear absorption corrections made by $8 \times 8 \times 8$ Gaussian quadrature using subroutines written by C. W. Burnham [5] and adapted by B. Dickens; maximum and minimum corrections for absorption $=0.880$ and 0.963 (transmission factors). Intensity Data: number of reflections, 2356 collected from 3 octants and merged into a unique set of 765 , of which 619 are "observed" and 146 are "unobserved"; unobserved reflections are those less than $2 \sigma$ above background; maximum $\sin \theta / \lambda$ for data $0.907 \AA^{-1}$; method used to estimate data: $\theta-2 \theta$ scan, scintillation counter; diffractometer: Picker ${ }^{2}$ 4-circle single-crystal diffractometer automated by PDP 8/I computer through FACS-1 interface and adapted to include least significant digit of counts; Computation: setting programs, those of reference [6] as adapted by Picker Nuclear Corporation; scan range: $1.4^{\circ}+114.6 \frac{\Delta \lambda}{\lambda}, \Delta \lambda=0.692$, $\lambda=0.70926 \AA$; scan parameters: backgrounds counted at higher and lower $2 \theta$ for $100 \mathrm{~s}$ each; $\theta-2 \theta$ scan at

${ }^{2}$ Certain commercial equipment, instruments, or materials are identified in this paper in order to adequately specify the experimental procedure. In no case does such identifica tion imply recommendation or endorsement by the National Bureau of Standards, nor doe it imply that the material or equipment identified is necessarily the best available for the purpose. 
$0.25^{\circ} \mathrm{min}$ for $2 \theta$ from one background position to the other; attenuators: $00.25 \mathrm{~mm}$ thick layers of $\mathrm{Nb}, 2$ layers for first attenuator, 4 for second, 6 for third; scan range correction: table look-up method to obtain values recommended in reference [7]; intensity data on paper tape, processed by program written by B. Dickens for Univac 1108 computer; this program contains adaptations of subroutines written for similar program by F. A. Mauer (NBS), standard reflection plotting routine and extinct reflection editing routine from programs by J. M. Stewart, University of Maryland, and uses an intense standard reflection (at low $2 \theta$ angle) measured every 50 reflections to correct for any change in intensity of the primary $\mathrm{x}$-ray beam. Counts in peak $=I=P-\left(T / 2 T_{\mathrm{B}}\right)\left(B_{\mathrm{L}}+B_{\mathrm{H}}\right), \sigma(I)=\left[P+\left(B_{\mathrm{L}}\right.\right.$ $\left.\left.+B_{\mathrm{H}}\right)\left(T /\left(2 T_{\mathrm{B}}\right)\right)^{2}\right]^{1 / 2}, \quad F=[(A F)(L P)(I)]^{1 / 2}, \quad \sigma(F)$ $=(\sigma(I) / 2)(L P / I)^{1 / 2}, L P=2$ sin $2 \theta_{c} /\left(\cos ^{2} 2 \theta_{m}+\cos ^{2}\right.$ $\left.2 \theta_{c}\right), \beta=-1.58883 \times 10^{6}\left[\lambda^{2}\left(\cos ^{2} 2 \theta_{m}+\cos ^{4} 2 \theta_{c}\right)\right.$ $d A / d \mu] /\left[A V^{2} \sin ^{2} \theta_{c}\left(\cos ^{2} 2 \theta_{m}+\cos ^{2} 2 \theta_{c}\right)\right]$ (for extinction corrections, calculated at same time as absorption correction). $P=$ counts at the peak position, $B_{\mathrm{L}}$ and $B_{\mathrm{H}}=$ background counts at lower and higher $2 \theta$ respectively, $T=$ time spend counting peak, $T_{\mathrm{B}}=$ time spent counting each background, $A F=$ attenuator factor, $L P=$ Lorentz-polarization correction, $\theta_{c}=$ Bragg angle for reflection under consideration, $\theta_{m}=$ Bragg angle for monochomator ( $=6.005^{\circ}$ here), $A=$ transmission factor in the absorption correction, $\mu$ is the linear absorption coefficient, $d A / d \mu$ is in $\mathrm{mm}, V$ is the volume of the unit cell in $\mathrm{A}^{3}$. Data merging program for equivalent reflections, written by B. Dickens for Univac 1108 computer; in this program each set of equivalent reflections is treated as follows: Reflections which were all unobserved were averaged and given the largest individual standard deviation in the set. Unobserved reflections in the presence of at least one observed reflection were discarded. Observed reflections which occurred only once in the reflection list subsequent to this step were copied unchanged but their standard deviations were increased by a factor of three. Observed reflections with magnitudes which agreed within the counting statistics and reflections with magnitudes whose ratios fell within the range 0.95 to 1.06 were averaged and given as standard deviation the maximum of the standard deviation from counting statistics and the standard deviation from the range estimate $[8,9]$. Under these circumstances, reflections whose magnitudes did not pass the criteria were discarded. If no members of a set of equivalent reflections passed the criteria, the highest magnitude was taken and the associated standard deviation multiplied by five. The justification for these arbitrary increases of standard deviation is that, without some corroboration, every reflection is suspect because of the possibilities of multiple reflection, including the "tail" of nearby intense reflections in its measurement, change in intensity of x-ray beam during reflection measurement, misalignment of crystal, etc. Since we usually measure three sets of equivalent reflections with care the number of standard deviations increased in this way is very small. Scattering factors: those for the neutral atoms in reference [10]; least-squares refinements: full-matrix, with $\Sigma w\left(\left|F_{o}\right|-\left|F_{c}\right|\right)^{2}$ minimized; refinements include unobserved reflections which calculate higher than $2 \sigma$ above background; least-squares weights: $1 / \sigma^{2}(F) ; R_{w}=\left[\Sigma w\left(\left|F_{\mathrm{o}}\right|-\left|F_{c}\right|\right)^{2} / \Sigma w\left|F_{\mathrm{o}}\right|^{2}\right]^{1 / 2}$, $R=\Sigma|| F_{\mathrm{o}}|-| F_{\mathrm{c}} \| / \Sigma\left|F_{\mathrm{o}}\right| ;$ thermal parameters have the form $\exp \left[-1 / 4\left(a^{*_{2}} B_{11} h^{2}+b^{*_{2}} B_{22} k^{2}+c^{* 2} B_{33} l^{2}\right.\right.$ $\left.\left.+2 a^{*} b^{*} B_{12} h k+2 a^{*} c^{*} B_{13} h l+2 b^{*} c^{*} B_{23} k l\right)\right]$. Most least squares and electron density synthesis calculations were carried out with the X-ray 67 system [11] of computing programs.

Final Refinement: $R_{w}=0.024 ; R=0.040$, average shift/error for last cycle $=0.0017$; standard deviation of an observation of unit weight

$$
=\left[\Sigma w\left(F_{\mathrm{o}}-F_{\mathrm{c}}\right)^{2} /(765-28)\right]^{1 / 2}=0.775 .
$$

The structure was refined isotropically from the positions given by Bragg to $R_{w}=0.031, R=0.047$, and then anisotropically to $R_{w}=0.024, R=0.040$. The low value of $R_{w}$ supports the earlier indications that the crystal used in the data collection is not twinned. The highest peak in an electron density difference synthesis calculated after anisotropic refinement to $R_{w}=0.024$ corresponded to about $1 / 3$ of an electron and was about 0.95 A from $\mathrm{C}$ towards $\mathrm{O}(1)$. The largest correlation coefficients are $0.34-0.44$ between the scale factor and the $B_{11}, B_{22}$ and $B_{33}$ temperature factors of $\mathrm{Ca}$.

Two cycles of least squares refinement in which the isotropic secondary extinction parameter $r$ in $F^{2}=F_{\text {unc }}^{2} /\left(1+\beta \mathrm{r}\left|F_{\text {unc }}\right|^{2}\right)$ was varied [12] together with all other unconstrained parameters resulted in no change in $R_{w}$ or $R$ and gave a value of $-0.3(9) \times 10^{-8}$ for the extinction parameter. There was no significant change in the structural details or their standard deviations. Thus, we believe secondary extinction to be negligible in our crystal of aragonite. Only the observed reflections were used in these refinements. Three cycles of least squares refinement in which allowance was made for the anomalous scattering of Ca (values taken from reference 10) gave an increase from 0.024 to 0.025 for $R_{w}$. $R$ was unchanged. There were no significant changes in the atomic positions.

The atomic parameters from the refinements without corrections for anomalous dispersion are given in table 1 . The observed and calculated structure factors are given in table 2 . The thermal parameters from the refinements which included corrections for the anomalous scattering of $\mathrm{Ca}$ are $\mathrm{Ca}$ : 0.71(1), 0.65(1), $0.65(1), 0.00,0.00,-0.01(1)$; C: 0.67(5), 0.80(6), 0.43(5), $0.00,0.00,0.08(5) ; 0(1): 1.45(5), 0.51(4), 1.01(5), 0.00$, $0.00,0.04(5) ; 0(2): 0.67(3), 0.98(3), 1.00(3),-0.32(3)$, $-0.02(3),-0.09(3)$. Only those for Ca are significantly different from the values in table 1 . Distances and angles referred to in the paper were calculated using the values in table 1 .

\section{Description of the Structure}

The structure of aragonite, the main points of which are well known, is shown in figure 1 . The Ca ions lie in pseudohexagonal layers parallel to $(001)$ and the layer sequence is $\mathrm{ABAB}$. The $\mathrm{Ca}$ layers are separated by $\mathrm{CO}_{3}$ groups which lie in two layers parallel to $(001)$, and form columns parallel to [001]. 
TABLE 1. Atomic parameters in aragonite $\left(\mathrm{CaCO}_{3}\right)$

\begin{tabular}{l|c|c|c|c|c|c|r|r|r}
\hline \hline Atoms & $x$ & $y$ & $z$ & $B_{11}{ }^{*}$ & $B_{22}$ & $B_{33}$ & \multicolumn{1}{c|}{$B_{12}$} & \multicolumn{1}{|c|}{$B_{13}$} & $B_{23}$ \\
\hline $\mathrm{Ca}$ & 0.25000 & $0.58507(5)$ & $0.25974(6)$ & $0.664(9)$ & $0.599(9)$ & $0.601(9)$ & 0.0000 & 0.0000 & $-0.01(1)$ \\
$\mathrm{C}$ & .25000 & $.2386(2)$ & $.4148(3)$ & $.75(5)$ & $.85(5)$ & $.46(5)$ & .0000 & .0000 & $.07(5)$ \\
$\mathrm{O}(1)$ & .25000 & $.0770(2)$ & $.4043(2)$ & $1.50(5)$ & $.54(4)$ & $1.04(4)$ & .0000 & .0000 & $.03(4)$ \\
$\mathrm{O}(2)$ & $.4737(2)$ & $.3196(1)$ & $.4131(2)$ & $0.71(3)$ & $1.03(3)$ & $1.02(3)$ & $-0.32(3)$ & $-.02(3)$ & $-.09(3)$ \\
\hline
\end{tabular}

Figures in parentheses are standard errors in last significant figure quoted, and were computed in the final cycle of full-matrix leastsquares refinement.

*Thermal parameters are in $\AA^{2}$.
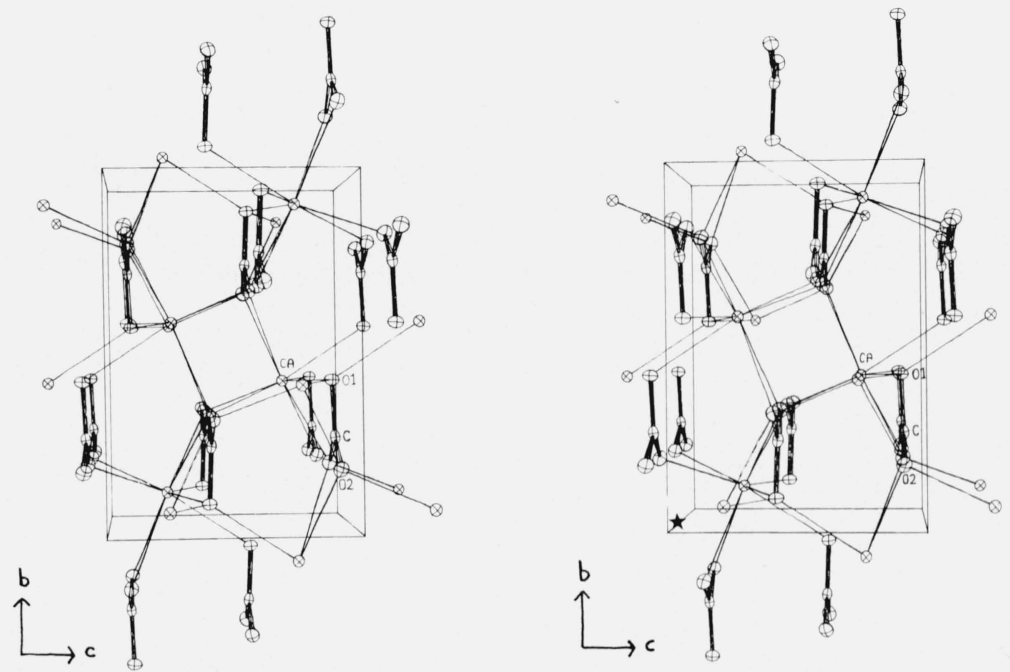

Figure 1. A stereoscopic illustration of the crystal structure of aragonite $\left(\mathrm{CaCO}_{3}\right)$.

A unique set of atoms is labeled. The origin of the crystallographic coordinate system is marked by *

\subsection{The Ca Ion Environments}

The Ca ion lies on the mirror plane at $x=1 / 4$. Its environment is shown in figure 2 and summarized in table 3 . The coordination of nine oxygens to $\mathrm{Ca}$ consists of three $\mathrm{CO}_{3}$ edges, $\mathrm{O}(1,2), \mathrm{O}\left(1^{1}, 2^{\mathrm{I}}\right)$ and $\mathrm{O}\left(2^{\mathrm{IV}}, 2^{\mathrm{V}}\right)$ and three apexes, $\mathrm{O}\left(1^{\mathrm{II}}, 2^{\mathrm{II}}, 2^{\mathrm{III}}\right)$. The apparent thermal motion of Ca is almost isotropic (table 1, fig. 2).

Corrections as given by Busing and Levy [13] to obtain the mean separation between atoms from the observed atomic positional and thermal parameters were calculated using a program written by Finger [12]. These corrections are included in tables 3 and 4 .

\subsection{The $\mathrm{CO}_{3}$ Group}

The details of the $\mathrm{CO}_{3}$ group and its environment are given in table 4 and shown in figure 3 . The positions reported by Bragg [3] give $\mathrm{C}-\mathrm{O}$ distances of $1.26 \mathrm{~A}$ and $1.30 \AA$, and $\mathrm{O}-\mathrm{C}-\mathrm{O}$ angles of $117^{\circ}, 117^{\circ}$ and $127^{\circ}$, which, under the circumstances, are all close to those reported here. The $\mathrm{C}-\mathrm{O}$ distances and $\mathrm{O}-\mathrm{C}-\mathrm{O}$ angles reported here for the $\mathrm{CO}_{3}$ group do not differ from each other significantly at the 95 percent confidence level; the same is true for the $\mathrm{O}-\mathrm{C}-\mathrm{O}$ angles. In view of the possibility of unknown systematic error, necessarily excluded from the calculations, our results therefore do not preclude trigonality of the $\mathrm{CO}_{3}$ group. Because the oxygens in the $\mathrm{CO}_{3}$ group have very similar environments, little deviation from trigonality is expected. The $\mathrm{CO}_{3}$ group is nonplanar however. The carbon atom is 0.026(4) $\AA$ out of the plane of the oxygen atoms in the $\mathrm{CO}_{3}$ group in aragonite. This displacement is approximately seven times the standard deviation and is clearly significant. The displacement is towards the nearest Ca layer and is presumably a result of polarization of each oxygen atom by the three bonded Ca ions. If the displacement were caused by $\mathrm{Ca}$. . . C interactions, the $\mathrm{C}$ atom would not move towards the Ca layer.

The difference in the $\mathrm{O}-\mathrm{C}-\mathrm{O}$ angles, $119.6^{\circ}$ and $120.13^{\circ}$, if real, is consistent with the $\mathrm{O}\left(2,2^{1}\right)$ edge of the $\mathrm{CO}_{3}$ group being coordinated slightly more strongly to $\mathrm{Ca}$ as judged from the $\mathrm{Ca}$. . . O distances. However, this stronger coordination of $\mathrm{O}(2)$ to $\mathrm{Ca}$ would also suggest that $\mathrm{C}-\mathrm{O}(2)$ should be longer than $\mathrm{C}-\mathrm{O}(1)$. This is not the case. The average value of the $\mathrm{C}-\mathrm{O}$ distances is $1.286 \hat{\mathrm{A}}$. This agrees well with the $\mathrm{C}-\mathrm{O}$ distances of 1.283(2) A reported [14] for calcite in which 32 symmetry is forced on the $\mathrm{CO}_{3}$ group by spacegroup $R \overline{3} c$. If the apparent thermal motions of the atoms in the $\mathrm{CO}_{3}$ group are attributed to thermal motion rather than to slight positional disorder, there 

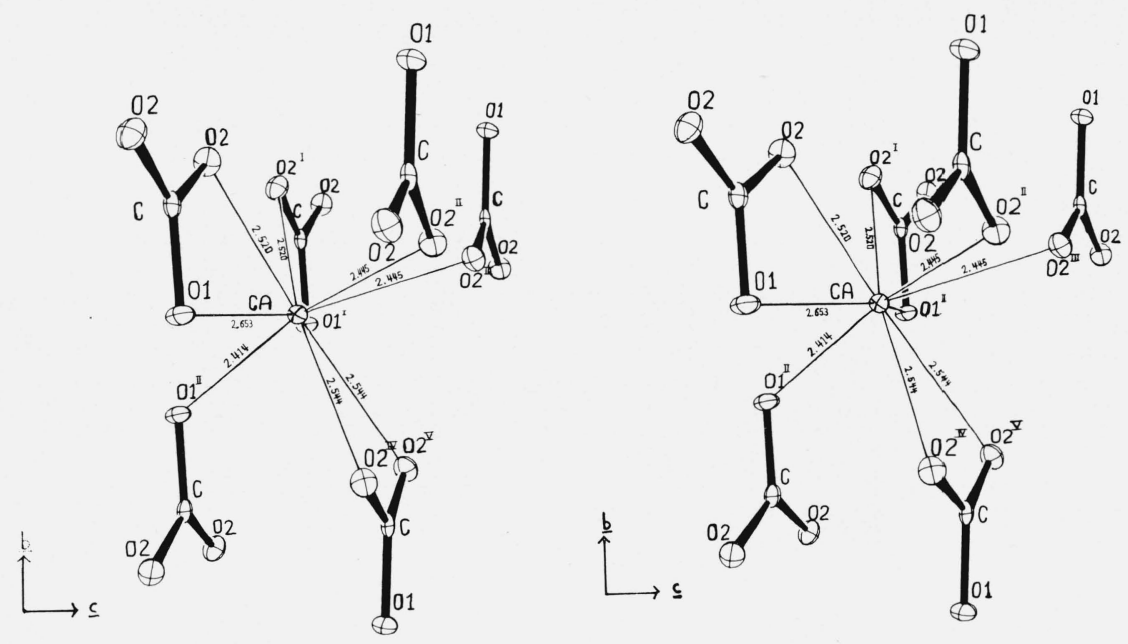

Figure 2. The $\mathrm{Ca}$ environment in aragonite $\left(\mathrm{CaCO}_{3}\right)$.
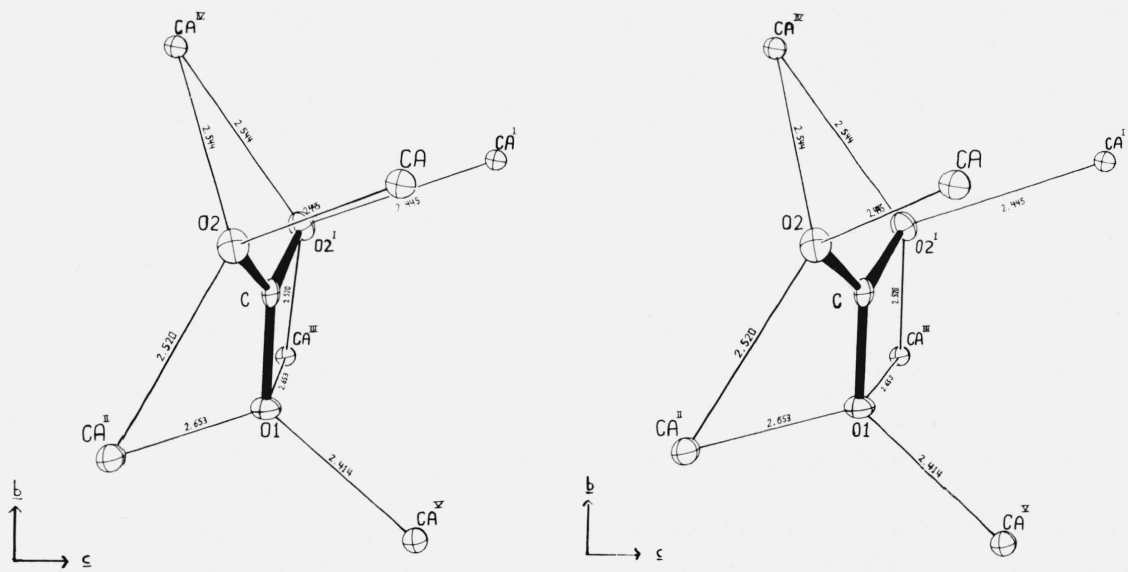

FigurE 3. The $\mathrm{CO}_{3}$ group environment in aragonite $\left(\mathrm{CaCO}_{3}\right)$.

The labels refer to atoms in table 4.

seems to be oscillation within the $\mathrm{CO}_{3}$ layer, i.e., more or less perpendicular to the edge coordination to Ca.

TABlE 3. The $\mathrm{Ca}$ environment in aragonite $\left(\mathrm{CaCO}_{3}\right)$

\begin{tabular}{l|c|c|c}
\hline \hline \multicolumn{1}{c|}{ Atoms } & $\begin{array}{c}\text { Distance, } \\
\text { A raw }\end{array}$ & $\begin{array}{c}\text { *Lower } \\
\text { bound [13] }\end{array}$ & $\begin{array}{c}\text { Noncorrelated } \\
\text { motion [13] }\end{array}$ \\
\hline $\mathrm{Ca}, \mathrm{O}\left(1^{1 \mathrm{II}}\right)$ & $2.414(2)$ & 2.414 & 2.423 \\
$\mathrm{Ca}, \mathrm{O}\left(2^{11}, 2^{\mathrm{III}}\right)$ & $2.445(1)$ & 2.445 & 2.454 \\
$\mathrm{Ca}, \mathrm{O}\left(2,2^{1}\right)$ & $2.520(1)$ & 2.520 & 2.527 \\
$\mathrm{Ca}, \mathrm{O}\left(2^{1 \mathrm{~V}}, 2^{\mathrm{V}}\right)$ & $2.544(1)$ & 2.544 & 2.551 \\
$\mathrm{Ca}, \mathrm{O}\left(1,1^{1}\right)$ & $2.653(1)$ & 2.653 & 2.660 \\
\hline
\end{tabular}

In all tables of interatomic distances and angles, the figures in parentheses are standard deviations in the last digit and were calculated from the standard deviations in the atomic positional parameters and the unit cell parameters.

* Mean separation between atoms when allowance is made for thermal motion.
Similarly, O(1) may be undergoing some additional wagging out of the $\mathrm{CO}_{3}$ layer.

TABLE 4. The $\mathrm{CO}_{3}$ group and its environment in aragonite $\left(\mathrm{CaCO}_{3}\right)$

\begin{tabular}{l|c|c|c}
\hline \hline \multicolumn{1}{c|}{ Atoms } & $\begin{array}{c}\text { Distance, } \\
\text { or angle, deg. }\end{array}$ & $\begin{array}{c}\text { Lower } \\
\text { bound [13] }\end{array}$ & $\begin{array}{c}\text { Riding } \\
\text { model [13] }\end{array}$ \\
\hline $\mathrm{C}, \mathrm{O}(1)$ & $1.288(2) \AA$ & $1.289 \AA$ & $1.295 \AA$ \\
$\mathrm{C}, \mathrm{O}(2)$ & $1.283(1)$ & 1.284 & 1.288 \\
$\mathrm{O}(1), \mathrm{O}(2)$ & $2.229(1)$ & & \\
$\mathrm{O}(2), \mathrm{O}\left(2^{1}\right)$ & $2.219(2)$ & & \\
$\mathrm{O}(1), \mathrm{C}, \mathrm{O}(2)$ & $120.13(8)^{\circ}$ & & \\
$\mathrm{O}(2), \mathrm{C}, \mathrm{O}\left(2^{1}\right)$ & $119.6(2)$ & & \\
$\mathrm{O}(1), \mathrm{Ca}^{\mathrm{I}}$ & $2.414(2) \AA$ & & \\
$\left.\mathrm{O}(1), \mathrm{Ca}^{11}, \mathrm{Ca}^{\mathrm{III}}\right)$ & $2.653(1)$ & & \\
$\mathrm{O}(2), \mathrm{Ca}$ & $2.445(1)$ & & \\
$\mathrm{O}(2), \mathrm{Ca}^{11}$ & $2.520(1)$ & & \\
$\mathrm{O}(2), \mathrm{Ca}^{\mathrm{IV}}$ & $2.544(1)$ & & \\
\hline
\end{tabular}


Table 2. Observed and calculated structure factors for aragonite (CaCo $\left.{ }_{3}\right)$

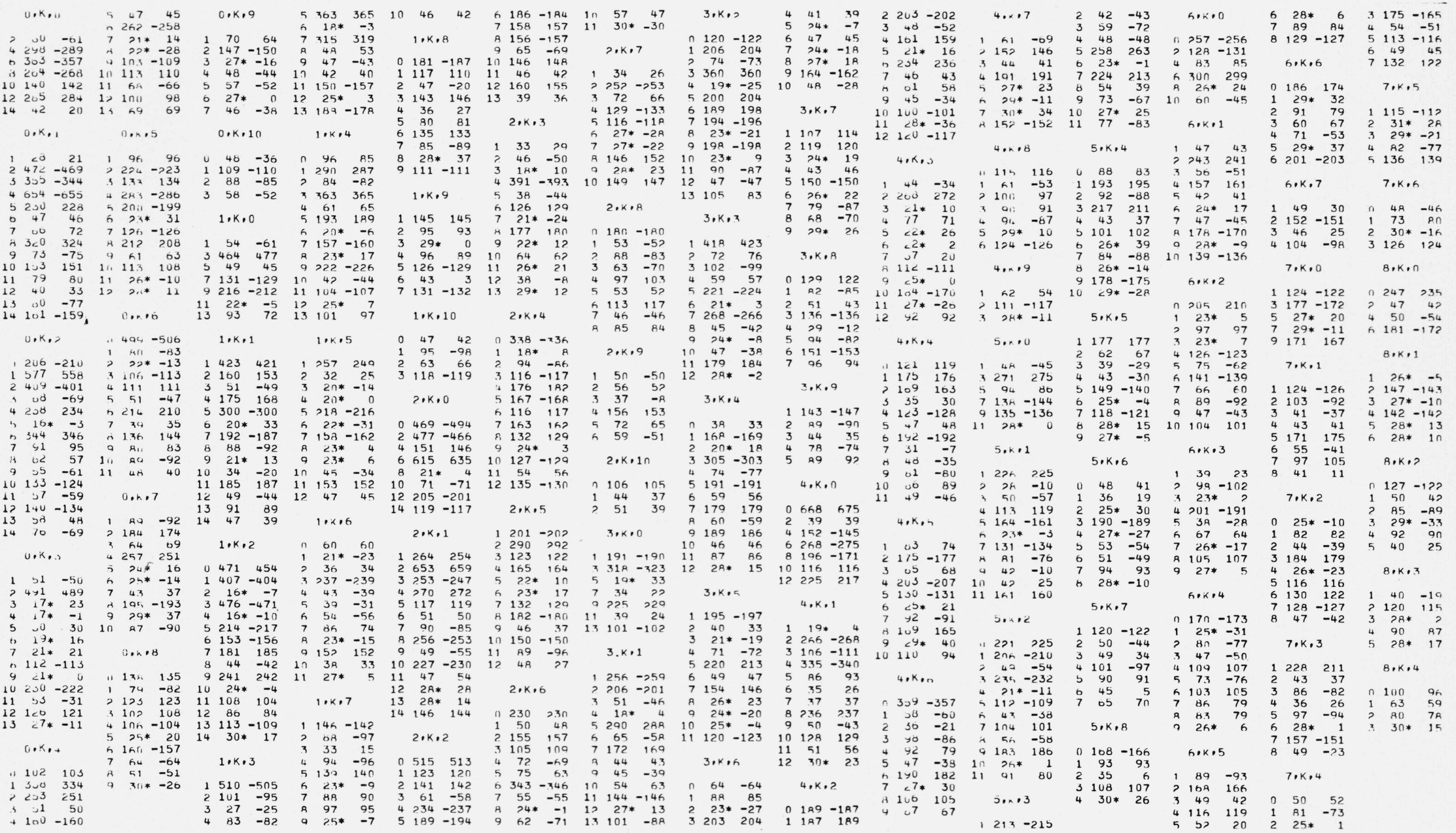

\footnotetext{
Columns are $\mathrm{K}, 10 \mathrm{~F}_{\mathrm{O}}, 10 \mathrm{~F}_{\mathrm{C}} \cdot \mathrm{F}_{\mathrm{O}}$ and $\mathrm{F}_{\mathrm{C}}$ are on an absolute scale. Reflections marked * are"unobserved".
} 
We thank W. E. Brown for helpful discussions and P. B. Kingsbury for technical help. The ORTEP program of C. K. Johnson, Oak Ridge National Laboratory, was used to draw the figures. This investigation was supported in part by research grant DE-00572 to the American Dental Association from the National Institute of Dental Research, and is part of the dental research program conducted by the National Bureau of Standards in cooperation with the American Dental Association; the United States Army Medical Research and Development Command; the Dental Sciences Division of the School of Aerospace Medicine, USAF; the National Institute of Dental Research; and the Veterans Administration.

\section{References}

[1] Palache, C., Berman, H., and Frondel, C.. Dana's system of mineralogy, vol. II, 7th ed., J. Wiley and Sons, N.Y. 1963, $182-193$.

[2] Busing, W. R., An aid to the analysis of interionic and intermolecular forces in crystals. Abstract M1. American Crystallographic Association winter meeting, Tucson, Arizona (1968).

[3] Bragg, W. L., The structure of aragonite. Proc. Roy. Soc. London, 105, 16-39 (1924).

[4] Reference [1], page 184.
[5] Burnham, C. W., Computation of absorption corrections and the significance of end effect. Am. Min., 51, 159-167 (1966).

[6] Busing, W. R., Ellison, R. D., Levy, H. A., King, S. P., and Roseberry, R. T., The Oak Ridge Laboratory Computercontrolled X-ray Diffractometer. Oak Ridge National Laboratory Report ORNL 4143, January 1968.

[7] Alexander, L. E., and Smith, G. S., Single crystal intensity measurements with the three circle counter diffractometer. Acta Cryst., 15, 983-1004 (1962).

[8] Ibers, J. A., Estimates of the standard deviations of the observed structure factors and of the electron density from intensity data. Acta Cryst., 9, 652-654 (1956).

[9] Tippett, L. H. C., On the extreme individuals and the range of samples taken from a normal population. Biometrika, 17, 364-387 (1925)

[10] International Tables for X-ray Crystallography, 3, p. 202. The Kynoch Press, Birmingham, England, 1962.

[11] Stewart, J. M., Editor. X-ray 67 program system for X-ray crystallography. Technical report 67-58, University of Maryland, College Park, Maryland 20742, December (1967).

[12] Finger, L. W., Determination of cation distribution by least squares refinement of single crystal x-ray data. Carnegie Institute of Washington Year Book, 67, 216-217 (1969).

[13] Busing, W. R., and Levy, H. A., The effect of thermal motion on the estimation of bond lengths from diffraction measurements. Acta Cryst., 17, 142-146 (1964).

[14] Chessin, H., Hamilton, W. C., and Post, B., Position and thermal parameters of oxygen atoms in calcite. Acta Cryst., 18, 689-693 (1965).

(Paper 75Al-647) 